\title{
Entre fuzis, cachaça e crucifixos: a catequese dos Munduruku no aldeamento do Bacabal (1872-1882)
}

Among Rifles, Cachaça and Crucifixes: The Catechism of Munduruku Indians in the Bacabal Village (1872-1882)

Marcio Couto Henrique*

Resumo: Em 1872, os Munduruku aderiram à missão do Bacabal, fundada pelo Frei Pelino de Castrovalva, no rio Tapajós. A expectativa do missionário era catequizá-los e civilizá-los, de modo a fazê-los detestar a "vida selvagem" e construir "a cidade dos Munduruku". Além dos conflitos com os índios aldeados, o capuchinho sofreu ataques dos comerciantes regatões, que viram seus interesses ameaçados pela tentativa do missionário de isolar os índios. Com base nas memórias do Frei Pelino de Castrovalva, em ofícios e jornais da época, analisa-se o modo como os Munduruku aderiram à missão do Bacabal, garantindo o acesso às desejadas mercadorias dos não indígenas, sem abrir mão de seus próprios projetos.

Palavras-chave: Munduruku; Frei Pelino de Castrovalva; Missão; Amazônia.
Abstract: In 1872, the Munduruku people entered the Bacabal mission, founded by Friar Pelino de Castrovalva, in the Tapajós River. The missionary expected to civilize and teach them catechism, in order to make them abhor the "savage life" and build "the Munduruku town". Besides conflicts with the resettled Indians, the capuchin friar suffered attacks from river merchants, who envisaged the missionary's attempt to isolate the Indians as a threat to their interests. Based on the memories of Friar Pelino de Castrovalva, on memos and on $19^{\text {th }}$ century newspapers, it is examined the means by which the Munduruku adhered to the Bacabal mission, ensuring the access to the intended non-indigenous commodities, notwithstanding the maintenance of their own goals.

Keywords: Munduruku; Friar Pelino de Castrovalva; Mission; Amazon.

\footnotetext{
* Universidade Federal do Pará (UFPA), Belém, PA, Brasil marciocouto@ufpa.br <https://orcid. org/0000-0002-0170-5315>
} 


\section{A CIDAde Dos MUNDURUKU ${ }^{1}$}

Em março de 1871, um grupo de capuchinhos desembarcou em Belém do Pará a fim de realizar a catequese dos índios da província. Dentre eles, Frei Pelino de Castrovalva foi designado para atuar como missionário entre os Munduruku do rio Tapajós, povo do tronco linguístico Tupi ${ }^{2}$. Era grande, àquela altura, a movimentação de comerciantes que se deslocavam do Mato Grosso ao Pará em busca dos produtos indígenas, especialmente o guaraná, produzido pelos Sateré-Mawé e Munduruku, e a missão seria um ponto estratégico de apoio à navegação e ao comércio da região (Muniz, 1906, p. 27).

A fama guerreira dos Munduruku era bastante conhecida. Eram os "cor-

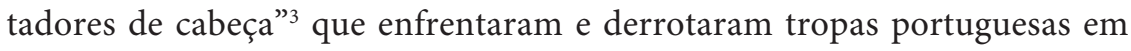
Santarém, em fins do século XVIII; que dificultavam a catequese dos demais índios; e que, em sua expansão guerreira, ameaçaram a capital da província, Belém, até o acordo de paz firmado com os colonizadores, a partir do que passaram a ser conhecidos como "amigos dos brancos" (Henrique, 2018). Frei Pelino dizia que os Munduruku "sobrepujam todos os demais em valor marcial. São jovens e robustos e mostram-se mansos em tempos de paz, mas indômitos e mui ferozes em tempo de guerra. Todos indistintamente andam nus" (Castrovalva, 2000, p. 74).

Em parte, a narrativa de Frei Pelino visava reforçar aos olhos de seus leitores europeus a grandeza de sua missão entre índios "selvagens"4. Disso resulta seu esforço em descrevê-los como "indômitos e ferozes em tempo de guerra", ou em afirmar que "todos indistintamente andam nus", muito embora roupas de algodão circulassem entre suas aldeias desde fins do século XVIII.

Frei Pelino partiu de Belém aos 23 de janeiro de 1872, acompanhado de Frei Antonino de Albano. Depois de cinco dias de viagem chegaram à vila de Itaituba, de onde partiram em direção aos índios. O primeiro contato com os Munduruku se deu treze dias depois da partida de Itaituba. O lugar escolhido para a fundação da missão foi o Bacabal, à margem direita do rio Tapajós. Frei Pelino deixou Frei Antonino na missão e partiu em direção às campinas, núcleo central de habitação dos Munduruku, onde chegou depois de 16 dias de viagem. Para convencê-los a se reunirem na missão, o missionário lhes disse que seu plano era:

fundar uma grandiosa missão para civilizar os Munduruku e fazer deles uma nação potente e gloriosa. 
Nós dissemos que sabíamos que eles pertenciam a uma antiga e gloriosa tribo, que realizou grandes feitos e que possuíamos maravilhosos segredos para lhes revelar e que, se nos dessem ouvido, nós os ajudaríamos a se tornarem poderosos e verdadeiramente grandes (Castrovalva, 2000, p. 81).

O discurso de convencimento utilizado por Frei Pelino procurava alimentar o ideal guerreiro dos Munduruku, cujo plano de civilização implicaria em transformá-los em "uma nação potente e gloriosa". Na verdade, o missionário prometia o retorno a um passado glorioso, já que ele diz saber que esses indígenas "pertenciam a uma antiga e gloriosa tribo, que realizou grandes feitos". Ora, os "grandes feitos" desse povo foram as guerras movidas contra outros povos indígenas e, também, contra os próprios colonizadores não indígenas.

Ao chegar às malocas dos índios que o acompanhavam, Frei Pelino, por meio de um intérprete, procurou explicar a finalidade de sua visita:

Relembrei o antigo valor dos Munduruku, nação que foi sempre guerreira e invencível e que fez um nome na história do Brasil por uma heróica resistência às tropas portuguesas, quando estes tiveram a ousadia de penetrar naquele lugar para ofender e subjugar seus direitos, mas que, repelidos para Santarém, foram obrigados a se refugiar sob a bateria dos canhões e, depois de terem feito um terrível estrago, os Munduruku voltaram vitoriosos (Castrovalva, 2000, p. 81).

Mais uma vez, o missionário apelou para o espírito guerreiro dos Munduruku. Na condição de funcionário do Império, Frei Pelino se referiu às guerras realizadas por esse povo como determinantes para a sua entrada na história do Brasil, mas teve o cuidado de direcionar sua "heróica resistência" contra os portugueses, símbolos da opressão colonial. Ao mesmo tempo, o religioso constrói a imagem dos Munduruku como injustiçados, cuja glória e cujo antigo valor ele estava ali para recuperar:

Fi-los entender que nós tínhamos ido libertá-los e salvá-los daquele estado desolador, enviados por dois grandes senhores: um deles chamado Deus, criador do Céu e da Terra e o outro, um poderoso Imperador que reinava na terra. Disse-lhes que Deus amava intensamente os índios selvagens e nos confiara segredos, que nós lhes devíamos comunicar. O Imperador nos pedira que fundássemos aí uma grande cidade, a cidade dos Munduruku, onde seria despertado antigo valor para fazê-los poderosos frente aos homens e destarte debelar e aniquilar seus inimigos. Se estivessem prontos a se mostrarem filhos dóceis, nós de boa vontade assumiríamos a tarefa de pais extremosos... (Castrovalva, 2000, p. 86). 
Frei Pelino se apresentava como escolhido de dois grandes senhores, Deus e o Imperador, para fundar a "cidade dos Munduruku", onde eles recuperariam seu antigo valor guerreiro, aniquilando seus inimigos tradicionais. Notese que as promessas do religioso eram todas de glórias mundanas: guerras, derrotas de seus inimigos, poder, sem qualquer referência ao projeto de catequese dos índios que se esperava dos missionários. De todo modo, o discurso do capuchinho apontava para a outra dimensão da atuação dos missionários, em comum acordo com a expectativa das autoridades do Império: a civilização dos índios. É nesse sentido que se deve compreender a ideia de se construir a "cidade dos Munduruku", marco indicativo do futuro civilizado desse povo.

Na nota dos objetos que deveriam ser fornecidos para a missão do Bacabal constam pano para calças e camisas, tecidos de chita para saias, pentes para homens e mulheres, espelhos, machados, terçados, enxadas, facas, linha, agulhas, tesouras, panelas, pregos, ferramentas para carpinteiro, farinha, rede de pescar, cachaça, pólvora e chumbo, espoletas, espingardas, lenços, chapéus (Mazzarino, 1872). Este era o instrumental civilizado inicial utilizado para apresentar aos índios as supostas vantagens da vida na cidade.

Reuniram-se, então, no Bacabal, 500 Munduruku. Para garantir a autossuficiência do aldeamento, Frei Pelino incentivou o plantio de diversas espécies:

Todo tuxaua tinha o seu grande campo. Já por toda parte surgiam delicadas e graciosas plantas frutíferas, a mandioca porfiava com o café, o algodão, as laranjas e os limões, as goiabas, perobas e cajus, os feijões, as melancias e as abóboras, as bananas, o milho e os ananás cobriam extensos campos e apresentavam um belíssimo panorama verdejante, ridente e luxuriante (Castrovalva, 2000, pp. 101-102).

A produção de farinha do aldeamento do Bacabal chegou a alterar a oferta e, principalmente, o preço do produto na região. De acordo com Tavares, os Munduruku fabricavam mais de 5 mil alqueires de farinha anualmente,

com o que bastante vão lucrando os comerciantes e regatões do alto Tapajós. Não há muito tempo era ali vendido um alqueire de farinha por quinze a dezesseis procedentes de Belém, hoje, o obtém por três e quatro mil reis fabricada pelos Munduruku (Tavares, 1876, p. 38).

A ênfase dos autores que discorriam a respeito das trocas comerciais com os índios recai, geralmente, sobre os lucros dos comerciantes. Em todo caso, deve-se registrar que, mesmo de forma desigual, o lucro dos comerciantes equivalia à entrada de mais mercadorias nas aldeias Munduruku. 
Uma das estratégias para intensificar, nos Munduruku, o desejo pelas mercadorias não indígenas e pela vida nas cidades, era levá-los até a capital da província, Belém. Dizia Frei Pelino:

Os que me acompanhavam à cidade voltavam a mim remunerados de mãos cheias em roupas, vestimentos novos e de luxo e outras coisas que pudessem aumentar a curiosidade e a impressão dos demais índios quando tivessem chegado à missão.

(...) Permitindo estas prolongadas reuniões eu conseguia dois alvos nobilíssimos: o primeiro era de acender cada vez mais nos índios o desejo de formarem eles, também, uma cidade. E, em segundo lugar, lhes fazer detestar a vida selvagem (Castrovalva, 2000, pp. 105-106).

Gonçalves Tocantins registrou a passagem de um grupo de Munduruku em Belém, portando produtos coletados na floresta para trocar com os comerciantes:

Agora mesmo leio em um acreditado jornal da capital do Pará a seguinte notícia: "Índios. Vieram a esta capital apresentar-se à presidência e promover a venda de 292 arrobas (mais de 4 mil quilogramas) de borracha, um cacique e 16 índios Munduruku, aldeados na missão do Bacabal.

O fardamento do cacique, bem como a pintura da cara desses índios tem provocado a curiosidade do povo" (Tocantins, 1877, p. 147).

Note-se a atitude performática do cacique ao se apresentar fardado diante do Presidente da Província, de modo a demonstrar sua autoridade, ostentando os símbolos de distinção que lhe foram conferidos pelo missionário, com o aval da autoridade maior da província. Por outro lado, o episódio nos permite constatar que os Munduruku também comercializavam a borracha diretamente em Belém, sem a intermediação de Frei Pelino.

Frei Pelino registrou que "a missão tem o aspecto de próspero e ameno vilarejo há pouco constituído e promete tornar-se, em breve, uma das mais atraentes cidadezinhas do Brasil" (Castrovalva, 2000, p. 235). Muito embora discordasse do ar de prosperidade indicado pelo capuchinho, Rufino Tavares descreveu o que viu na missão do Bacabal, em 1876:

Uma casa assobralhada, coberta de palha, bastante espaçosa, com alguns compartimentos assoalhados, serve de vivenda aos missionários. Uma parte foi desti- 
nada para a capela consagrada à Nossa Senhora da Misericórdia, servindo outras de escola e casa de arrecadação. Cerca de 70 meninos de ambos sexos frequentam a escola, onde, além dos exercícios religiosos, aprendem a ler, escrever e contar uma vez por dia (Tavares, 1876, p. 38).

Segundo Tavares, os Munduruku habitavam 15 barracões cobertos de palha, alinhados e voltados para a margem do rio Tapajós. Assim como observou Izabel Missagia de Mattos com relação à atuação dos capuchinhos junto aos Botocudos, em Minas Gerais, "a convergência da utopia missionária com o projeto de 'civilização' da nação planejada pelos administradores das políticas indigenistas pode ser observada na concepção de aldeamento indígena como o gérmen de uma futura e próspera cidade" (Mattos, 2004, p. 260) ${ }^{5}$. A garantia de construção da "cidade dos Munduruku", a partir de onde esses índios recuperariam seu antigo valor e poderiam aniquilar seus inimigos com o apoio de Deus, do Imperador e dos missionários, tinha um preço: eles deveriam aceitar a condução do processo como "filhos dóceis", sujeitando-se à vontade dos missionários.

\section{NO MEIO DO CAMINHO TINHA O REGATÃo}

O centro de todo o comércio entre os Munduruku e os regatões era a, então, vila de Itaituba, inicialmente habitada por Sateré-Mawé e Munduruku, que abasteciam os regatões de Santarém com guaraná, óleo, cravo e salsaparrilha - essa última, "reputada como a melhor de todo o Pará e Amazonas" (Tavares, 1876, p. 15). Era em Itaituba que os cuiabanos se supriam, anualmente, de guaraná.

Para limitar o contato dos índios com os regatões, o capuchinho adotou as seguintes medidas: nenhum regatão poderia pernoitar na missão sem sua permissão. Em caso de extrema necessidade, deveria ser "vigiado por toda a noite por um grupo de nove ou dez índios armados, por mim escolhidos, e de minha confiança"; os regatões só poderiam negociar e frequentar as casas dos índios com o consentimento do missionário; e, por fim, nenhum deles poderia construir casa ou acampamento nos limites da missão (Castrovalva, 2000, pp. 112-113).

Para punir regatões e índios rebeldes, Frei Pelino também construiu uma "casa de punição", na qual aprisionou diversos regatões. Para auxiliar na vigilância e na disciplina do aldeamento, solicitou ao Presidente da Província "patente e farda de capitão para um valente tuxaua, meu amigo e oito fardas mi- 
litares para oito robustos jovens índios da missão, formando com eles um pelotão de sete soldados e um cabo e um capitão, sob o meu comando" (Castrovalva, 2000, pp. 112-113).

O fornecimento de farda aos tuxauas ou "principais" das aldeias era prática comum desde o Brasil colonial, apesar de não ser previsto no Decreto de 24 de julho de 1845, que regulamentava a atividade missionária no Brasil. Era uma forma de distinguir simbolicamente as lideranças indígenas e promover a disciplina nos aldeamentos. Assim, procurava-se incrementar o poder de lideranças favoráveis, interferindo nas dinâmicas das políticas indígenas ${ }^{6}$. $\mathrm{O}$ tuxaua capitão do Bacabal era Mary-Baixy, conhecido e temido pelas dezenas de assassinatos que havia cometido. Tal qual ocorria no Brasil colonial, veremos mais adiante que Mary-Baixy transitou entre a condição de principal aliado e a de principal inimigo de Frei Pelino.

Com as medidas de isolamento da missão, não tardaram a chegar ameaças de morte aos dois missionários. Em março de 1877, o periódico Baixo Amazonas denunciou que Frei Pelino havia metido nos troncos um jovem regatão, "por ter tido a audácia de entrar na praça do comércio de Frei Pelino - Aldeamento do Bacabal - para receber de um índio um paneiro com farinha!" (A Província do Pará, 1877, p. 1). Revoltados, os regatões decidiram invadir o aldeamento. Ao saber disso, Frei Pelino disse ao companheiro, Frei Antonino: "O crucifixo está comigo, me dê sua arma, que a minha não está comigo. E, soltando meu braço de sua mão, apanhei de cima da mesa seu revólver, coloquei-o no bolso e dirigi-me aos regatões" (Castrovalva, 2000, pp. 115-116). Frei Pelino não apenas armou os Munduruku como, também, exercia sua missão armado. Quando um dos regatões que invadiu a missão quis levar um Munduruku que supostamente devia dinheiro a outro regatão, já falecido, o missionário reagiu energicamente:

Não sei o que me impede de esfacelar tua cabeça! E quem és tu, que tens o topete de falar assim na minha missão? Sabes tu com quem estás falando e diante de quem tu te encontras? É frente a um italiano, que deseja mostrar-te hoje qual é o sangue que corre em minhas veias! (Castrovalva, 2000, p. 117).

Em outro momento de tensão, os regatões ameaçaram invadir a missão do Bacabal na noite de Natal. O capuchinho ordenou que os Munduruku fizessem uma fila de fogueiras às margens do rio Tapajós e, nelas, enfileirou 75 jovens Munduruku, todos armados de fuzil. Além disso, armou outra patrulha, de dez jovens, chefiados por Mary-Baixy. Depois disso, disse ele: "eu e frei 
Antonino apanhamos nossos fuzis de dois canos e nossos revólveres, mas sobretudo, nossos crucifixos" (Castrovalva, 2000, p. 119). Diante desse pelotão armado, os regatões recuaram dizendo que "não queriam comer chumbo" (Castrovalva, 2000, p. 120).

\section{O TEOR BÉLICO-ALCOÓLICO DA MISSÃO DO BACABAL}

Se Marta Amoroso (2006b) se refere ao "teor alcoólico" da catequese entre os Kaingang e Kaiowá, pode-se dizer que, no aldeamento do Bacabal, a catequese tinha um teor bélico-alcoólico. A prática de solicitar armas como brindes a serem dados aos índios era comum entre outros missionários da Amazônia no período, o que indica a importância que elas adquiriram nessas relações. Poucas vezes esses pedidos eram negados pelas autoridades.

As armas dadas aos índios eram financiadas pela verba destinada à chamada catequese e civilização dos índios e pode-se ter uma ideia da quantidade delas e das munições que entravam na missão do Bacabal a partir das listas de objetos pedidos por Frei Pelino. Uma matéria de tom sarcástico, publicada no jornal O Liberal do Pará, em 1872, chamava a atenção do leitor para a presença de muitas armas e munição no pedido de mercadorias feito por Frei Pelino para iniciar a missão do Bacabal:

Entre a grande coleção de objetos indispensáveis para uma campanha religiosa desta ordem, figuram uma ambulância suficiente para curar todos os gentios desta quarta parte do mundo, revólveres, espingardas, pólvoras e uma grande variedade de outras mercadorias europeias (O Liberal do Pará, 1872, p. 1).

Segundo o articulista, as mercadorias foram entregues aos missionários,

com exceção apenas das espingardas, cujo número pedido fora de 100, e da pólvora de que pediram 10 barris, cuja quantidade foi reduzida a 30 espingardas e a 1 barril de pólvora, por ter sido com esta despesa esgotado o crédito da respectiva verba (O Liberal do Pará, 1872, p. 1).

Em se tratando do primeiro pedido de mercadorias feito por Frei Pelino, pode-se dizer que o tom bélico de sua missão entre os Munduruku existiu desde o início do aldeamento. Apesar das críticas do jornal, o fornecimento de armas ao aldeamento do Bacabal continuou. Em 26 de agosto de 1875, o missionário solicitou ao Presidente da Província que efetuasse o pagamento de 
"alguns objetos de necessidade" que ele adquiriu em Itaituba, entre os quais citava cinco caixas de espoletas (Castrovalva, 1875c). Após o naufrágio que sofreu em uma das cachoeiras do rio Tapajós, no mesmo ano, Frei Pelino fez novo pedido de mercadorias para a missão, entre as quais solicitava o envio de cinco barris com pólvora, oito barris com chumbo, seis armas potentes e uma arma de dois canos (Castrovalva, 1875b). No episódio em que o capuchinho enfileirou os Munduruku para o ataque aos regatões, ele se refere a 75 jovens armados de fuzis e mais a uma patrulha de dez jovens igualmente armados. Considerando que o total de índios reunidos no aldeamento do Bacabal era de cerca de 500, nota-se que era grande a quantidade de armas existentes no espaço da missão.

Outra via de acesso dos Munduruku a armas de fogo eram os regatões. Gonçalves Tocantins apresentou uma conta à qual ele teve acesso durante sua viagem ao aldeamento do Bacabal. Entre os itens devidos pelo Munduruku Joaquim Correia Piampé, constavam dois barris de pólvora; três arrobas de chumbo, seis milheiros de espoleta e " 5 armas fulminantes". O Munduruku José Francisco da Boa-Vista devia a um regatão, entre outras coisas, uma enxó de fuzil, três dúzias de colheres de chumbo, uma barrica com 25 libras de pólvora, meia arroba de chumbo, 20 ouvidos para armas e dez armas fulminantes finas (Tocantins, 1877, p. 152).

Um fato vivenciado por Gonçalves Tocantins na aldeia de Nicodemos serve de indicativo do fascínio que as armas de fogo exerceram sobre esses indígenas. Tocantins se interessou por uma cabeça miniaturizada que viu em mãos de um índio Munduruku, que não queria trocá-la por nada. Como último recurso, Tocantins lhe ofereceu uma espingarda:

Só me fez entrega desta relíquia no último momento, quando eu já estava embarcado para descer o Caderery e, nessa ocasião, disse, ainda: "Mas eu a queria para mim!" Também eu lhe tinha feito presente de uma espingarda de dois canos, de pólvora, chumbo e outros objetos. Assim mesmo, nos acompanhou com a vista até a canoa desaparecer pelo rio abaixo (Tocantins, 1877, p. 85).

Ao comentar o impacto das armas de fogo sobre as armas tradicionais dos Munduruku, Charles Frederick Hartt fez um interessante relato:

(...) todas estas armas aborígenes estão sendo rapidamente substituídas por armas de fogo. Vi uma vez um lote de 120 barris de pólvora com destino às campinas para negócio de barganha (...). A posse de armas de fogo dá-lhes hoje uma imensa superioridade sobre seus inimigos mais selvagens (Hartt, 1885, p. 131). 
Note-se que as armas às quais Hartt se refere tinham como destino as aldeias situadas nas campinas, o núcleo mais afastado de habitação dos Munduruku, no alto Tapajós, sobre o qual os missionários não tinham ingerência.

Com relação ao teor alcóolico da missão do Bacabal, também era alimentado por regatões e pelo Frei Pelino ${ }^{7}$. Na conta entre um regatão e o Munduruku Joaquim Correia Piampé, consta que, entre os itens devidos pelo indígena, constavam "8 frasqueiras de cachaça com garrafão". Por sua vez, o Munduruku José Francisco da Boa Vista devia nove fraqueiras de cachaça, duas garrafas de licor e seis frascos de vinho tinto (Tocantins, 1877, p. 154).

Por um lado, o missionário condenava a oferta de cachaça aos índios quando feita pelos regatões, acusando-os de promover "bailes e orgias infernais” para roubar os produtos dos Munduruku (Castrovalva, 2000, pp. 110111). Por outro, é possível acompanhar a presença de cachaça nas listas de pedido que ele apresentava à presidência da província do Pará. Logo após ter sofrido naufrágio, Frei Pelino solicitou "10 garrafões com cachaça". Em outro pedido, seis meses depois, ele solicitou "quatro frasqueiras de cachaça" (Castrovalva, 1875c). Chama atenção o fato de que esses pedidos eram atendidos sem questionamento por parte da presidência da província, talvez por compreenderem como normal o uso da cachaça nas relações com os índios. Afinal, tratava-se de item sempre presente nas embarcações que percorriam os rios da Amazônia, muitas vezes utilizado como moeda de troca, seja por viajantes ou por regatões (Henrique; Morais, 2014).

Reproduzindo as críticas e acusações nem sempre fundamentadas dos regatões, Abreu dizia que "a missão se convertera em uma bacanal em que a embriaguez, a prostituição e o roubo disputavam a palma entre si” (Abreu, 1883, p. 63). A presença da cachaça também foi apontada por Barbosa Rodrigues (1875) como uma das causas de extinção dos aldeamentos Munduruku. Na verdade, Frei Pelino e os regatões se acusavam mutuamente quanto ao uso da cachaça como elemento de desestruturação da ordem no aldeamento do Bacabal.

Em resposta à tentativa de Frei Pelino de isolar os Munduruku, os regatões criaram um jornal em Santarém, intitulado O Baixo Amazonas, no qual publicaram constantes ataques ao missionário, acusado de fazer comércio para si com a borracha produzida pelos índios, vender aos índios objetos fornecidos pelo governo, manter relações ilícitas com mulheres Munduruku e de enviar altas quantias de dinheiro para a Europa (O Pelicano, 1873, p. 3).

Em $1^{\circ}$ de março de 1874 , os comerciantes de Itaituba enviaram à Assembleia Legislativa do Pará uma reclamação formal, queixando-se de que 
Frei Pelino monopolizava o trabalho dos índios, descuidando-se da catequese (Tocantins, 1877, p. 135). Dois anos depois, o tuxaua Vicente, que costumava vender borracha sem a mediação de Frei Pelino, foi ouvido pelo chefe de polícia no interrogatório sobre as acusações que os regatões faziam contra o missionário. Por intermédio de seu intérprete Manoel Munduruku, o tuxaua, quando perguntado "em que tempo saiu ele respondente do Bacabal e o que veio fazer a esta capital?”,

respondeu que há um mês pouco mais ou menos e veio comprar sal, armas, pólvora, chumbo, fazendas para roupa, açúcar e diversos utensílios para seu trabalho de roça; e que para esse fim trouxe em dinheiro quinze notas de cem mil reis e quatro de cinquenta, que recebeu do tenente Joaquim Caetano Corrêa, de Itaituba, em pagamento de uma partida de borracha que lhe vendeu (A Província do Pará, 1876, p. 2).

Note-se que os objetos que o tuxaua Vicente pretendia comprar em Belém eram os mesmos que geralmente constavam nas listas de pedidos apresentadas por Frei Pelino à presidência da província. Nesse caso, Vicente já chegou a Belém com dinheiro em mãos, por ter vendido "uma partida de borracha" para um comerciante em Itaituba.

Apesar de afirmar que Frei Pelino não o proibia de vender sua borracha em Belém, o tuxaua Vicente Munduruku fez duas acusações contra o capuchinho: "frei Pelino tem tido ilícitas com a mulher de seu companheiro de nome João Mathias Floriando e que ele sabe por ter visto e presenciado" e "que o frade prende, às vezes, para castigar, as mulheres e o meninos da aldeia" (O Liberal do Pará, 1876, p. 1). Outros três Munduruku apresentaram acusações contra o frei missionário.

Ao se defender das acusações, Frei Pelino procurava deslegitimar os índios que o acusavam e dizia que o intérprete, Manoel Quirino, havia sido cooptado pelos regatões:

Este rapaz, sendo de pouco boa vida, desobediente e rebelde, que quase nunca está na missão, e o único que ainda não quer deixar o comércio com os regatões, tem sido por estes motivos por mim várias vezes exprobrado e castigado... (A Boa Nova, 1877, p. 1).

Esse episódio revela que havia índios Munduruku que discordavam das posições de Frei Pelino, apresentando projetos próprios quanto à exploração e à venda da borracha. Era o caso do tuxaua Vicente e de Manoel Quirino, o 
intérprete "de pouco boa vida, desobediente e rebelde" aos olhos do capuchinho, razão pela qual fora castigado.

A situação se tornou desfavorável a Frei Pelino quando ele foi acusado de fraudar um fornecimento de brindes aos índios do Bacabal, retirando mais produtos do que constavam na lista de pedidos autorizada pela presidência da província. Em 24 de fevereiro de 1876, o missionário foi afastado do cargo de diretor do aldeamento. Os Munduruku participaram ativamente de todo esse processo, depondo ora contra, ora a favor do capuchinho.

Enviado pelo Presidente da Província para averiguar o estado da missão, o Dr. Adriano Pimentel apresentou um relatório no qual não poupou críticas ao missionário:

Como verificará V. Exc. da relação junta, por mim tirada com grande dificuldade, visto não haver um arrolamento, nem assentos de batismos, casamentos e óbitos, cujos livros me foram entregues em branco, existem atualmente no Bacabal 502 indígenas, sendo 152 homens, 152 mulheres e 198 crianças dos dois sexos (Jornal do Pará, 1877, p. 1).

Estando em branco, os livros nos quais deveriam constar os assentos de batismos, casamentos e óbitos foram utilizados como prova de que Frei Pelino não estava se dedicando como deveria ao trabalho de catequese dos índios. $\mathrm{O}$ relatório de Pimentel reforçava as acusações dos regatões contra o missionário: Frei Pelino comercializava a borracha para si, estimulava a embriaguez entre os índios e isolou os Munduruku do contato com os regatões, os quais tratava com violência, enfraquecendo o comércio local. Uma segunda comissão foi enviada, chefiada por Antonio Gonçalves Tocantins, para avaliar o estado da missão e as ações do missionário, especialmente com relação à suposta fraude no fornecimento de brindes ao Bacabal.

\section{“Os ÍNDiOs RESOLVERAM MUDAR O SISTEMA"}

Destituído do cargo de diretor dos índios, mas permanecendo na condição de missionário, Frei Pelino decidiu se envolver diretamente na exploração dos produtos da floresta, incentivando os Munduruku a coletar os produtos e vendê-los sem a intermediação dos regatões. Em um mês, os índios extraíram 1.680 litros de copaíba, que foram enviados à casa comercial de Diniz Cullére, que realizou a venda em Belém sem pedir comissão, apenas para beneficiar os índios. Com o dinheiro adquirido, o missionário comprou tecidos, espingar- 
das, pólvoras, machados, enxadas, pratos, açúcar, café, entre outros produtos distribuídos aos índios que haviam coletado a copaíba (Tocantins, 1877, p. 158). Disse Frei Pelino:

Por todo o ano de 1879 continuou o sistema de mandar borracha para o Pará e depois com o lucro se fazia virem as mercadorias. Mas, no ano de 1880, os índios resolveram mudar o sistema e propuseram que se fizesse vir antecipadamente as mercadorias e eles, na época da colheita, mandariam a borracha em pagamento, justificando que com tal procedimento não estariam obrigados a recorrer aos regatões em caso de urgente necessidade, os quais se aproveitariam de sua emergência para os explorar e roubar (Castrovalva, 2000, p. 161).

Na verdade, o "sistema" habitual era exatamente o que os índios defendiam que retornasse: primeiro, os Munduruku recebiam as mercadorias e, em seguida, pagariam com os produtos da floresta. Conforme registrou o viajante inglês Bates, os comerciantes precisavam primeiramente distribuir as suas mercadorias e, depois, esperar três ou quatro meses para receber o pagamento dos índios (Bates, 1979, p. 181). O "sistema" segundo o qual primeiramente era enviada a borracha para a capital da província e, com o lucro, eram compradas as mercadorias desejadas pelos índios, foi uma inovação feita por Frei Pelino, ávido por exercer o controle sobre as negociações e dificultar o acesso dos regatões aos produtos indígenas. A expressão "os índios resolveram mudar o sistema” é um exemplo claro do protagonismo dos Munduruku, exigindo que o missionário adequasse todo o processo à dinâmica tradicional das trocas indígenas. Assim, eles garantiam a oferta imediata de mercadorias e exerciam controle sobre o tempo de duração do pagamento.

Garantindo o sistema de receber as mercadorias antes e pagar depois, os Munduruku exerciam controle maior sobre o uso de seu tempo, conciliando as coletas dos produtos com atividades tradicionais que garantiam o sustento de suas famílias ao longo do ano, além das guerras realizadas contra outros povos indígenas.

A experiência dos Munduruku com a coleta da borracha, seja sob a administração de Frei Pelino ou por conta própria, revela uma dimensão ainda pouco estudada da história da Amazônia: a participação dos índios na coleta do principal produto de exportação da região entre meados do século XIX e início do século XX: o látex.

O envolvimento dos Munduruku na coleta dos produtos da floresta e a atração pelas mercadorias advindas desse comércio são, de um modo geral, 
percebidos indiretamente na documentação. Pode-se deduzir o envolvimento dos índios a partir do número de Munduruku aldeados no Bacabal, que girava em torno de 500 a 700 e, também, do número de "tuxauas" referidos por Frei Pelino nas negociações. Quando decidiu compensar o governo da província pelos produtos excedentes que levou à missão, solicitando aos índios que coletassem produtos na floresta, Frei Pelino afirmou ter mantido contato com 22 tuxauas, cada um deles representante de várias famílias. A quantidade de produtos coletados, seja de borracha ou de óleo de copaíba, também sugere a participação de muitos Munduruku.

Para Murphy e Murphy, “o motivo básico dos movimentos migratórios para as regiões do baixo Madeira e Tapajós parece ser o desejo dos índios de obterem artigos manufaturados, especialmente utensílios de ferro" (Murphy; Murphy, 1954, p. 10). Conforme Henrique e Morais (2014), costuma-se definir o papel dos índios nas relações de trocas com os regatões sempre como vítimas ingênuas da astúcia dos comerciantes. Ao se enfatizar o valor comercial, desconsidera-se o valor simbólico das mercadorias entre esses povos. Desse modo, os produtos recebidos pelos índios são, geralmente, definidos como "quinquilharias" (Tavares, 1876, p. 31), "bugigangas", "produtos sem nenhum valor", sem que se perceba que a noção de valor é uma construção cultural.

Por essa razão, os índios costumam ser referidos como povos que "não sabem o valor das coisas" e que, por isso, se deixam enganar facilmente. Muitas vezes, as coisas que os índios mais valorizavam entre os objetos da cultura material não indígena reforçavam esse estereótipo (Henrique, 2017). Ao se referir aos Munduruku, Hartt dizia que "devido ao comércio da borracha e salsaparrilha do alto Tapajós, os índios agora estão providos de colares e ornatos" (Hartt, 1885, p. 123), objetos que, aos olhos dos "brancos", seriam destituídos de valor, quinquilharias.

Parte dos objetos que os Munduruku permutavam com os regatões, ou que solicitavam às autoridades, era destinada às mulheres das aldeias, as quais, segundo Frei Pelino, "são mais exibidas que os homens. Amam o luxo e os adornos...” (Castrovalva, 2000, p. 204). Ao comentar a atitude do francês De Lincourt, "que tentou corromper uma rapariga Munduruku", Hartt observou que o francês ofereceu a ela braceletes, colares de pérolas falsas, mas "tudo foi inútil. A rapariga Munduruku era superior ao francês” (Hartt, 1885, p. 127). Além da violência cometida por De Lincourt, o relato revela, também, o apreço das mulheres Munduruku por colares e braceletes de miçanga, utilizados na tentativa de seduzir a indígena ${ }^{8}$. Nas listas de objetos solicitados para a missão do Bacabal, Frei Pelino costumava inserir "pentes para mulheres", te- 
cidos de chita para saias, além de outros produtos, revelando-se o respeito às vontades das mulheres Munduruku nas relações comerciais com não índios.

\section{MARY-BAIXY: O ALIADO INCORRIGÍVEL}

Ao mesmo tempo em que deixava os Munduruku satisfeitos com a maior quantidade de mercadorias que recebiam em troca dos produtos que coletavam, Frei Pelino causava a ira dos regatões. Em 1881, um carregamento de borracha enviado a Belém foi desviado por dois regatões em Itaituba (Castrovalva, 2000, p. 162). Depois de uma série de conflitos, uma denúncia foi apresentada contra Frei Pelino, acusado de usurpar a borracha que pertencia aos Munduruku. A denúncia estava assinada por um índio Munduruku, José da Gama Mary-Baixy. O capuchinho procurou desqualificar a importância dessa assinatura, referindo-se a Mary-Baixy como

um índio da missão o qual, embora não estivesse em boas relações comigo, em razão de ser incorrigível, tendo entre outros crimes, mais de vinte homicídios na consciência, como mais adiante ele próprio haverá de confessar e embora eu o tivesse muitas vezes expulso da missão, todavia ele não queria assinar, mas no fim caiu na trama dos astuciosos regatões (Castrovalva, 2000, pp. 166-167).

Ora, trata-se do mesmo índio para o qual Frei Pelino solicitou patente e espada de capitão, logo no início da missão, e a quem o missionário se referiu como "meu amigo" e "valoroso tuxaua". Frei Pelino disse ter solicitado a patente de capitão para José da Gama Mary-Baixy "pela sua dedicação no serviço da Missão e pelo zelo em manter a ordem pública, e porque é o que lá goza maior influência". A patente era solicitada "a fim de que possa exercer este ofício com maior desvelo e legitimidade” (Castrovalva, 5 fev. 1875a). A relação entre Frei Pelino e Mary-Baixy foi marcada por muitas tensões e revela que o capitão do Bacabal nem sempre estava disposto a se submeter aos projetos do capuchinho.

Quando prestou depoimento ao chefe de polícia em Belém, Mary-Baixy admitiu ter assassinado um homem e que, por essa razão, havia sido expulso por Frei Pelino. Disse ele: "matei alguns, mas... isto lá é meu costume". Espantado, o chefe de polícia quis saber quantos ele havia matado: "matei pouco mais de vinte", respondeu o capitão do Bacabal. Frei Pelino registrou que o chefe de polícia ficou horrorizado diante daquele "homem de proporções colossais, de uma força hercúlea, de índole cruel, de aspecto feroz", que afir- 
mava ter matado mais de 20 pessoas "com um frio e cínico sorriso" (Castrovalva, 2000, p. 172). Assustado, o chefe de polícia se dirigiu ao capuchinho:

- Padre mestre, não me traga mais Mary-Baixy, pois eu já o examinei bastante. Ao que respondi:

- O senhor viu um só... e eu que me encontro no meio deles...

Terminada a necessária inquirição o chefe de polícia decidiu e sentenciou a meu favor e determinou que me restituíssem a borracha roubada (Castrovalva, 2000, pp. 172-173).

Quando lhe pareceu conveniente, Frei Pelino não se importou em distinguir Mary-Baixy com patente e farda de capitão, mesmo sabendo que aquele indígena havia assassinado mais de 20 pessoas. Mas, quando o conflito se instaurou entre os dois, Mary-Baixy não era mais citado pelo missionário em função de "sua dedicação no serviço da Missão e pelo zelo em manter a ordem pública”, como afirmou ao reivindicar a ele a patente de capitão. Ao contrário, o religioso tratava de enfatizar sua "índole cruel", seu "aspecto feroz", expulso tantas vezes do aldeamento por se mostrar “incorrigível”. Por outro lado, de algum modo o capitão Munduruku tirava proveito dessa imagem de índio "selvagem", ao ponto de não ser preso mesmo tendo confessado mais de 20 mortes segundo seu "costume".

Frei Pelino dizia que, entre os Munduruku, "a magia é a causa de todos os males", crença que seria "muito fomentada pelos sacerdotes, a que chamam de pajé" (Castrovalva, 2000, p. 205). Por outro lado, os pajés estavam sob o risco permanente de serem acusados de feitiçaria e provocarem a morte de alguém, estando igualmente sujeitos à morte por causa disso. Tocantins narrou um episódio em que o jovem Ismael Munduruku foi acusado de feitiçaria: "o rapaz foi morto com dois tiros de espingarda, acabando-o com pancadas na cabeça" (Tocantins, 1877, p. 108), a mando de Mary-Baixy. Veja-se como, apesar de tantos assassinatos cometidos por esse indígena, Frei Pelino não hesitava em deixar o aldeamento do Bacabal sob sua direção quando precisava se ausentar da missão por muitos dias. Por outro lado, muitas mortes foram cometidas utilizando as armas que os Munduruku conseguiam com missionários e regatões, como vimos no caso de Ismael. Tal era o prestígio de MaryBaixy entre os Munduruku que, ao deixar o aldeamento do Bacabal, após a visita de inspeção que fez ao aldeamento, o engenheiro Adriano Pimentel o deixou encarregado da administração da missão. A ele, o jornal O Liberal do 
Pará se referiu como "O tuxaua-mor José da Gama Mary-Baixy" (O Liberal do Pará, 1877, p. 1).

Frei Pelino afirmou que, durante os dez anos em que esteve na condição de missionário no Bacabal, soube da morte de oito pessoas acusadas de feitiçaria. Depois da oitava morte, o capuchinho reuniu todos os tuxauas e muitos pajés e fez a eles a seguinte ameaça: ou eles paravam com tais práticas, ou o capuchinho faria uma denúncia ao governo, exigindo que todos os culpados por mortes de supostos feiticeiros passassem o resto de suas vidas na prisão. Depois disso, segundo o missionário, os pajés começaram a se articular para assassiná-lo, liderados pelo tuxaua Vicente.

O famoso capitão Mary-Baixy, o mais valente, o mais honesto que havia, sempre instável e feroz, abandonou a minha companhia porque eu o havia reprovado por ocasião da morte do último jovem (que era de sua família) havendo ele mesmo cooperado em trucidá-lo por ordem do pajé (...)” (Castrovalva, 2000, pp. 217-218).

Em outras situações, Frei Pelino parecia não se importar com as ações violentas de Mary-Baixy. Em 1878, o capuchinho ordenou a partida de uma "bandeira de Munduruku", sob o comando de Mary-Baixy, para pôr fim a uma "correria" de índios Juremas que resultou na morte de mais de 20 destes, além do aprisionamento de outros 14 (O Liberal do Pará, 1878, p. 1). Nesse caso, Mary-Baixy comandava uma "bandeira Munduruku", fazendo uso das armas que recebia do missionário e dos regatões para atacar povos indígenas inimigos.

Em fins do século XIX, o viajante francês Coudreau encontrou MaryBaixy, "um velho Munduruku bastante famoso", vivendo em uma maloca no chamado Igarapé do Cantagalo, no rio Tapajós, e trabalhando com sua gente nos seringais e nas plantações.

o velho selvagem, que fala muito bem o português, aprendeu o que sabe com os mestres da esperteza, os mercadores do rio, chamados "regatões", aos quais seria hoje capaz, dizem, de dar quinau. Não lhe reprovam, no lugar, a sagacidade de um grego ou de um tuaregue com a qual resolve seus negócios; contudo acham que ele age com pouco tato quando se vangloria publicamente de ter feito justiça sumária acerca de uns vinte Munduruku que estorvavam a liberdade de movimentos de sua orgulhosa existência (Coudreau, 1977, p. 37).

Ainda velho, Mary-Baixy seguia trabalhando na exploração da borracha, garantindo o fluxo de mercadorias à sua comunidade. A partir de sua "experiência dos brancos" (Yanomami; Albert, 1999), especialmente com os rega- 
tões, ele aprendeu o suficiente para não mais ser visto como ingênuo ou como alguém facilmente enganado por "bugigangas". Ao contrário, era respeitado e definido como um índio esperto, capaz de enganar ou de tirar proveito dos próprios "mestres da esperteza", os regatões com quem ele aprendeu a negociar. E, assim como fez diante do chefe de polícia, em Belém, Mary-Baixy continuava se vangloriando de ter assassinado mais de 20 parentes seus.

\section{À GUISA DE CONCLUSÃO}

Ao se despedir dos Munduruku que visitou em 1875, Gonçalves Tocantins afirmou que

A última hora ainda insisti com estes selvagens para que viessem ver nossas cidades, ou ao menos para que mandassem alguns de seus filhos, comprometendo-me eu a fazê-los regressar mais tarde para a companhia de seus pais.

Alguns apenas responderam por um sinal negativo e outros nem sequer responderam, como se não considerassem o convite digno de ser tomado em consideração (Tocantins, 1877, p. 161).

A “cidade dos Munduruku” planejada por Frei Pelino de Castrovalva não se realizou. Os pajés continuaram em ação, os índios Munduruku continuaram estabelecendo relações com os regatões por conta própria e os guerreiros continuaram atacando povos inimigos, matando homens adultos e raptando mulheres e crianças. Ao longo do século XIX, os Munduruku se abasteceram dos mais variados tipos de mercadorias ocidentais, sejam as que receberam como brindes do governo imperial, sejam as que conseguiram em suas relações com os comerciantes regatões. Alguns deles visitaram mais de uma vez a maior cidade da Amazônia, Belém.

Mercadorias como armas de fogo, cachaça e roupas deixaram marcas profundas no modo de ser desse povo. Em pesquisa de campo feita nos anos 1950, Murphy e Murphy afirmaram que as maiores alterações ocorreram na esfera da cultura material, deslocando-se muitos objetos da manufatura do grupo, ao passo que se solidificou a dependência dos Munduruku em relação ao comércio com os não indígenas (Murphy; Murphy, 1954, p. 13).

De todo modo, como em outras partes do Brasil, a introdução maciça de objetos manufaturados nas aldeias implicou em "mudança de hábito" (Amoroso, 1998), em “metamorfoses indígenas" (Almeida, 2013 [2003]), mas não significou a transformação dos Munduruku em "civilizados”. Ao contrário, 
eles foram capazes de se apropriar das mercadorias não indígenas de modo a reinventar o modo de ser Munduruku. Ao focalizar o modo como as sociedades indígenas interpretam o contato colonial em seus próprios termos, os índios surgem como protagonistas e não mais como vítimas passivas da suposta assimilação ao sistema econômico ocidental (Comaroff; Comaroff, 1991).

Conforme Manuela Carneiro da Cunha, muitas vezes, acessar as mercadorias dos não indígenas constitui uma forma de "pacificar os brancos", de

situá-los, aos brancos e aos seus objetos, numa visão de mundo, esvaziá-los de sua agressividade, de sua malignidade, de sua letalidade, domesticá-los, em suma; mas também entrar em novas relações com eles e reproduzir-se como sociedade, desta vez não contra, e sim através deles, recrutá-los em suma para sua própria continuidade (Cunha, 2002, p. 7).

Assim, os índios operam a chamada "indigenização da modernidade" (Sahlins, 1997; Gordon, 2006). No caso específico dos Munduruku, não pode ser desprezado o fato de que eles "sempre tiveram como valor positivo a possibilidade de usufruir das benesses do mundo dos brancos, sem abdicar das formas próprias de compreensão do mundo" (Ramos, 2011, p. 398). Assim, tornar-se civilizado aos olhos dos Pariwat (não indígenas) era um convite que eles nem sequer consideravam digno de ser tomado em consideração. Conforme atestou Tocantins, a gênesis Munduruku indicava a aldeia de Nicodemos como sendo "o berço do gênero humano" (Tocantins, 1877, p. 75). Não o berço dos índios, apenas, mas o berço da humanidade, criada por seu mito fundador, Karusacaibô. Os Munduruku não precisavam das supostas vantagens da civilização para se sentir uma nação potente e gloriosa, nem de um herói que os libertasse de sua suposta escravidão.

\section{REFERÊNCIAS}

ABREU, José Coelho da Gama e. A Amazônia: as províncias do Pará e Amazonas, e o governo central do Brazil. Lisboa: Typographia Minerva, 1883.

ALMEIDA, Maria Regina Celestino de. Metamorfoses indígenas: identidade e cultura nas aldeias coloniais do Rio de Janeiro. Rio de Janeiro: FGV, 2013 [2003].

AMOROSO, Marta Rosa. Mudança de hábito: Catequese e educação para índios nos aldeamentos capuchinhos. Revista Brasileira de Ciências Sociais, v. 13, n. 37, São Paulo, pp. 101-114, 1998. 
AMOROSO, Marta Rosa. A primeira missa: memória e xamanismo na Missão Capuchinha de Bacabal (Rio Tapajós, 1872-1882). In: MONTERO, Paula (Org.). Deus na aldeia: missionários, índios e mediação cultural. São Paulo: Globo, 2006a. pp. 209-233.

AMOROSO, Marta Rosa. Crânios e cachaça: coleções ameríndias e exposições no século XIX. Revista de História, São Paulo, n. 154, pp. 119-150, 2006b.

A BOA NOVA, Belém, 3 jan. 1877, p. 1.

BATES, Henry Walter. Um naturalista no rio Amazonas. Belo Horizonte: Itatiaia, São Paulo: EDUSP, 1979.

CASTROVAlva, Frei Pelino de Castrovalva. Ofício do frei Pelino de Castrovalva, missionário capuchinho, para Francisco $M^{a}$ Corrêa de Sá e Benevides, Presidente da Província do Pará, Belém; Secretaria da Presidência da Província, Série 13. Belém (Arquivo Público do Pará). 5 fev. 1875a.

CASTROVAlva, Frei Pelino de Castrovalva. Ofício do frei Pelino de Castrovalva, missionário capuchinho, para Francisco $\mathrm{M}^{\mathrm{a}}$ Corrêa de Sá e Benevides, Presidente da Província do Pará, Cachoeira das Furnas; Secretaria da Presidência da Província. Série 13. Belém (Arquivo Público do Pará). 24 fev. 1875b.

CASTROVAlva, Frei Pelino de Castrovalva. Ofício do frei Pelino de Castrovalva, missionário capuchinho, para Francisco $M^{a}$ Corrêa de Sá e Benevides, Presidente da Província do Pará, Itaituba; Secretaria da Presidência da Província, Série 13. Belém (Arquivo Público do Pará). 26 ago. 1875c.

CASTROVALVA, Frei Pelino de. O rio Tapajós, os capuchinhos e os índios mundurucus (1871-1883). São Luís, MA: [s. n.], 2000.

COMAROFF, Jean; COMAROFF, John L. Of Revelation and Revolution: Christianity, Colonialism, and Consciousness in South Africa. Vol. 1. Chicago: University of Chicago Press, 1991.

COUDREAU, Henry. Viagem ao Tapajós. Belo Horizonte: Itatiaia; São Paulo: EDUSP, 1977.

CUNHA, Manuela Carneiro da. Apresentação. In: ALBERT, Bruce; RAMOS, Alcida Rita (Orgs.). Pacificando o branco: cosmologias do contato no norte-amazônico. São Paulo: Editora UNESP; Imprensa oficial do Estado, 2002. pp. 7-8.

FERNANDES, João Azevedo. Selvagens bebedeiras: álcool, embriaguez e contatos culturais no Brasil colonial (séculos XVI-XVII). São Paulo: Alameda, 2011.

GORDON, Cesar. Economia Selvagem: ritual e mercadoria entre os índios Xikrin-Mebêngôkre. São Paulo: ISA/NUTI/UNESP, 2006.

HARTT, Charles Frederik. Contribuições para a ethnologia do Valle do Amazonas. Archivos do Museu Nacional do Rio de Janeiro. Vol. VI, Rio de Janeiro: Typ. e Lith. Economica, de Machado \& C, 1885.

HENRIQUE, Márcio Couto. Sem Vieira nem Pombal: índios na Amazônia do século XIX. Rio de Janeiro: EdUERJ, 2018. 
HENRIQUE, Márcio Couto. Presente de branco: a perspectiva indígena dos brindes da civilização (Amazônia, século XIX). Revista Brasileira de História, São Paulo, v. 37, n. 75, pp. 195-216, 2017.

HENRIQUE, Márcio Couto; MORAIS, Laura Trindade de. Estradas líquidas, comércio sólido: índios e regatões na Amazônia (século XIX). Revista de História (USP), São Paulo, n. 171, pp. 49-82, 2014.

HOWARD, Catherine V. A domesticação das mercadorias. Estratégias Waiwai. In: ALBERT, Bruce; RAMOS, Alcida Rita (Orgs.). Pacificando o branco: cosmologias do contato no norte-amazônico. São Paulo: Editora UNESP; Imprensa oficial do Estado, 2002. pp. 25-60.

JORNAL DO PARÁ. Belém, 15 jun. 1877, p. 1.

LEOPOLDI, José Sávio. A guerra implacável dos Munduruku: elementos culturais e genéticos na caça aos inimigos. Avá (Posadas), Universidad Nacional de Misiones, n. 11, pp. 171-191, 2007.

MELO, Vinícius Zúniga. Os Diretores de Povoações: serviços e transgressões no Grão-Pará do Diretório dos Índios (1757-1798). Dissertação (Mestrado em História Social da Amazônia) - Instituto de Filosofia e Ciências Humanas, Programa de Pós-Graduação em História Social da Amazônia, Universidade Federal do Pará. Belém, 2016.

MENGET, Patrick. Notas sobre as cabeças Munduruku. In: VIVEIROS DE CASTRO, Eduardo; CUNHA, Manuela Carneiro da (Orgs.). Amazônia: Etnologia e História Indígena. São Paulo: USP - Núcleo de História Indígena e do Indigenismo/FAPESP, 1993. p. 311-321.

MATTOS, Izabel Missagia de. Civilização e revolta: os Botocudos e a catequese na Província de Minas. Bauru, SP: EDUSC, 2004.

MAZZARINO, Frei Ludovico de. Ofício do Frei Ludovico de Mazzarino, vice-prefeito dos Missionários Capuchinhos, para o Dr. Abel Graça, Presidente da Província do Pará, Belém; Secretaria da Presidência da Província, Série 13. Belém (Arquivo Público do Pará). 3 jan. 1872.

MUNIZ, João de Palma. O município de Itaituba. Belém: Typ. Guttenberg, 1906.

MURPHY, Robert F.; MURPHY, Yolanda. As condições atuais dos Mundurucú. Belém: Instituto de Antropologia e Etnologia do Pará, 1954.

O LIBERAL DO PARÁ, Belém, 26 jan. 1872, p. 1.

O LIBERAL DO PARÁ, Belém, 20 nov. 1876, p. 1.

O LIBERAL DO PARÁ, Belém, 30 mar. 1877, p. 1.

O LIBERAL DO PARÁ, 15 mai. 1878, p. 1.

O PELICANO, Belém, 23 mar. 1873, p. 3.

A PROVÍNCIA DO PARÁ, Belém, 20 dez. 1876, p. 2.

A PROVÍNCIA DO PARÁ, Belém, 16 mar. 1877, p. 1. 
RAMOS, André Raimundo Ferreira. O SPI na Amazônia: o caso exemplar da ação indigenista entre os Munduruku. In: FREIRE, Carlos Augusto da Rocha (Org.). Memória do SPI: textos, imagens e documentos sobre o Serviço de Proteção aos Índios (1910-1967). Rio de Janeiro: Museu do Índio-FUNAI, 2011. pp. 389-401.

RODRIGUES, Joaquim Barbosa. Exploração e Estudo do valle do Amazonas: Rio Tapajós. Rio de Janeiro: Typ. Nacional, 1875.

SAHLINS, Marshall. O "pessimismo sentimental" e a experiência etnográfica: porque a cultura não é um "objeto" em via de extinção (Parte I). Mana, v. 3, n. 1, pp. 41-73, 1997.

SAMPAIO, Patrícia Melo. Espelhos partidos: etnia, legislação e desigualdade na colônia. Manaus: EDUA, 2011 [2001].

SAMPAIO, Patrícia Melo. Política indigenista no Brasil imperial. In: GRINBERG, Keila; SALLES, Ricardo. O Brasil Imperial. Vol. I: 1808-1831. Rio de Janeiro: Civilização Brasileira, 2009. pp. 175-206.

SOMMER, Bárbara. Negotiated settlements: Native Amazonians and Portuguese Policy in Pará, Brazil, 1758-1798. PhD Thesis, University of New Mexico. New Mexico, 2000.

SPOSITO, Fernanda. Nem cidadãos, nem brasileiros: indígenas na formação do Estado nacional brasileiro e conflitos na província de São Paulo (1822-1845). Dissertação (Mestrado em História) - Faculdade de Filosofia, Letras e Ciências Humanas, Programa de Pós-graduação em História Social, Universidade de São Paulo. São Paulo, 2006.

TAVARES, Rufino Luiz. O rio Tapajós. Rio de Janeiro: Typographia Nacional, 1876. TOCANTINS, Antonio Manuel Gonçalves. Estudo sobre a tribu Mundurucú. Revista Trimensal do Instituto Histórico Geographico e Ethnographico Brasileiro, tomo XL, Rio de Janeiro: B. L. Garnier, pp. 73-161, 1877.

YANOMAMI, Davi Kopenawa; ALBERT, Bruce. Descobrindo os brancos. In: NOVAES, Adauto (Org.). A outra margem do Ocidente. São Paulo: Companhia das Letras, 1999. pp. 15-21.

\section{NOTAS}

${ }^{1}$ Pesquisa financiada por bolsa de produtividade do CNPq. Optei por padronizar o termo Munduruku ao longo do artigo, mantendo a grafia "Mundurucu" apenas nos títulos de trabalhos consultados.

${ }^{2}$ Marta Amoroso analisou a experiência missionária de frei Pelino de Castrovalva entre os Munduruku, com o objetivo de "identificar o lugar que as ideias de Deus e de Diabo ocupam em tais narrativas e fragmentos discursivos" (Amoroso, 2006a, p. 213). Nesse artigo, 
faço uso de documentação mais variada e inédita, focando na agência dos Munduruku e não no discurso do missionário.

${ }^{3}$ Sobre as cabeças mumificadas pelos Munduruku, conferir Murphy e Murphy, 1954; Menget, 1993; Leopoldi, 2007.

${ }^{4}$ As memórias de frei Pelino foram publicadas, antes, nos Annali Francescani. Conferir Castrovalva, 2000, pp. 35-36.

${ }^{5}$ Sobre a política indigenista no Brasil do século XIX, conferir Sposito, 2006; Sampaio, 2009; Henrique, 2018.

${ }^{6}$ Sobre as "hierarquias indígenas" na Amazônia colonial, conferir Sommer, 2000; Sampaio, 2011 [2001]; Melo, 2016.

${ }^{7}$ Sobre as formas nativas de experiência etílica, conferir Fernandes, 2011.

${ }^{8}$ Entre os WaiWai, as miçangas constituem "o item máximo de riqueza estrangeira. Elas representam beleza, juventude e fertilidade; as pessoas tornam-se sedutoras ao se enfeitar com elas" (Howard, 2002, p. 48). 